\title{
The targeted proteins in tumor cells treated with the a-lactalbumin- oleic acid complex examined by descriptive and quantitative liquid chromatography-tandem mass spectrometry
}

\author{
B. Fang, ${ }^{* 1}$ M. Zhang, † X. Fan,§ and F. Z. Ren†§ \\ *Beijing Advanced Innovation Center for Food Nutrition and Human Health, and \\ tKey Laboratory of Functional Dairy, College of Food Science and Nutritional Engineering, China Agricultural University, Beijing, 100083, China \\ ¥School of Food Science and Chemical Engineering, Beijing Technology and Business University, Beijing, 100048, China \\ §Beijing Laboratory for Food Quality and Safety, China Agricultural University, Beijing, 100083, China
}

\section{ABSTRACT}

An $\alpha$-lactalbumin-oleic acid ( $\alpha$-LA-OA) complex has exhibited selective antitumor activity in animal models and clinical trials. Although apoptosis and autophagy are activated and the functions of several organelles are disrupted in response to $\alpha-\mathrm{LA}-\mathrm{OA}$, the detailed antitumor mechanism remains unclear. In this study, we used a novel technique, isobaric tags for relative and absolute quantitation, to analyze the proteome of tumor cells treated with $\alpha$-LA-OA. We identified 112 differentially expressed proteins: 95 were upregulated to satisfy the metabolism of tumor cells; 17 were downregulated and targets of $\alpha-\mathrm{LA}-\mathrm{OA}$. According to the differentially expressed proteins, $\alpha$-LA-OA exerted its antitumor activity by disrupting cytoskeleton stability and cell motility, and by inhibiting DNA, lipid, and ATP synthesis, leading to cellular stress and activation of programmed cell death. This study provides a systematic evaluation of the antitumor activity of $\alpha$-LAOA, identifying its interacting targets and establishing the theoretical basis of $\alpha$-LA-OA for use in cancer therapy.

Key words: human alpha-lactalbumin made lethal to tumor cells (HAMLET), isobaric tag for relative and absolute quantitation (iTRAQ), antitumor, proteomics

\section{INTRODUCTION}

Despite recent advances in cancer treatment, a remaining issue is side effects for healthy cells. Human $\alpha$-lactalbumin made lethal to tumor cells (HAMLET) is a protein-fatty acid complex that was originally discovered in human milk, consisting of $\alpha$-LA and oleic

\footnotetext{
Received February 1, 2016.

Accepted April 14, 2016.

${ }^{1}$ Corresponding author: 49631263@qq.com
}

acid (Svensson et al., 2000). It exhibits an ability to kill a wide range of tumor cell types (Håkansson et al., 1995; Svensson et al., 2002; Hallgren et al., 2006) but to spare healthy, differentiated cells, both in vitro (Håkansson et al., 1995, 1999; Svensson et al., 2000) and in vivo (Fischer et al., 2004; Gustafsson et al., 2004; Mossberg et al., 2010a).

The molecular mechanism of the antitumor activity of HAMLET has been studied extensively (Svanborg et al., 2003; Gustafsson et al., 2009), and HAMLETlike complexes have been shown to induce apoptosis in tumor cells (Tolin et al., 2010; Fang et al., 2014, 2015). However, upon inhibition of pro-apoptotic caspase proteins or overexpression of anti-apoptotic proteins Bcl-2 and Bcl-xL, cell viability in response to HAMLET does not increase (Hallgren et al., 2006). Furthermore, the status of the apoptosis-dependent protein p53 does not change the antitumor activity of HAMLET (Hallgren et al., 2006). In addition to induction of apoptosis, HAMLET triggers cytoplasmic vacuolation and the formation of double membrane-enclosed vesicles, indicating typical macroautophagy (Aits et al., 2009). Although Aits et al. (2009) found that suppression of beclin-1 and ATG5 improves the survival of HAMLET-treated tumor cells, Zhang et al. (2013) recently demonstrated the opposite trend. Suppression of autophagy by inhibiting p62/SQSTM1, an important substrate of autophagosome enzymes, aggravates HAMLET-induced cell death, whereas activation of autophagy attenuates this process. Furthermore, inhibition of autophagy by 3-methyladenine with or without simultaneous inhibition of apoptosis by z-VAD-FMK (an inhibitor of the apoptosis pathway) does not prolong the survival of tumor cells treated with these $\alpha$-LA-fatty acid complexes (unpublished data). These results suggest a complicated mechanism for HAMLET-like complexes as antitumor drugs.

Proteomics analysis is widely applied to analyze diseases, especially cancer. Recently, a new approach called 
isobaric tags for relative and absolute quantitation (iTRAQ) has been developed, which overcomes the shortcomings of the classic 2-dimensional gel technique. An iTRAQ-based quantitative proteomics approach is unbiased toward proteins that are not amenable to the 2-dimensional gel technique and because they are too large or small, too acidic or basic, or too hydrophobic (Zieske, 2006; Fukao et al., 2011; Ghochani and Gilany, 2011).

In this study, we compared the quantitative and qualitative changes in proteomes that occurred in HeLa cells treated with bovine $\alpha$-LA-oleic acid complex ( $\alpha-\mathbf{L A}$ OA) using iTRAQ-based proteomics to determine the molecular mechanism of HAMLET-like complexes.

\section{MATERIALS AND METHODS}

\section{Materials}

Bovine $\alpha$-lactalbumin $\left(\mathrm{Ca}^{2+}\right.$-free; $85 \%$ pure, lot: L6010) and cell culture-tested oleic acid (OA; C18:1 cis-9, $\geq 99.0 \%$ pure) were obtained from Sigma-Aldrich (St. Louis, MO). The culture medium consisted of high glucose Dulbecco's modified Eagle's medium supplemented with fetal bovine serum, penicillin, and streptomycin (all from Gibco, Life Technology, Paisley, UK). All other chemicals used were analytical grade.

\section{Preparation of $\alpha-L A-O A$}

The HAMLET analog $\alpha$-LA-OA was prepared by heat treatment according to Fang et al. (2012).

\section{Cell Line and Cultures}

HeLa cells were purchased from the American Type Culture Collection (Manassas, VA) and maintained in Dulbecco's modified Eagle's medium, supplemented with $10 \%$ fetal bovine serum, $20 \mathrm{U} / \mathrm{mL}$ penicillin, 20 $\mu \mathrm{g} / \mathrm{mL}$ streptomycin, and $10 \mathrm{~m} M$ HEPES at $37^{\circ} \mathrm{C}$ with $5 \% \mathrm{CO}_{2}$.

\section{Protein Extraction}

The HeLa cells treated with $40 \mu M \alpha$-LA-OA for $24 \mathrm{~h}$ were digested with trypsin $(0.25 \%$, wt $/ \mathrm{vol})$ and harvested by centrifugation $\left(4^{\circ} \mathrm{C}, 300 \times g, 5 \mathrm{~min}\right)$. Cell pellets were washed 3 times with pre-cooled PBS and then resuspended in $1 \mathrm{~mL}$ of lysis buffer containing 7 $M$ urea, $2 M$ thiourea, and 4\% CHAPS (wt/vol, GE Healthcare, Buckinghamshire, UK). Cell suspensions were sonicated on ice using an ultrasonic processor (Scientz-IID, Ningbo Scientz Biotechnology Co., Ning- bo City, China) at $22 \%$ amplitude with 9 -s pulses at 9 -s intervals and then centrifuged at $15,000 \times g$ for $15 \mathrm{~min}$ at $4^{\circ} \mathrm{C}$. The supernatant was collected, and the protein concentration was quantified using the Bradford method (Carlsson et al., 2011).

\section{Protein Reduction, Alkylation, Trypsin Digestion, and ITRAQ Labeling}

Extracted proteins $(200 \mu \mathrm{g})$ were transferred into new tubes and reacted with $4 \mu \mathrm{L}$ of reducing reagent (AB Sciex Inc., Framingham, MA) for $1 \mathrm{~h}$ at $60^{\circ} \mathrm{C}$. Then, $2 \mu \mathrm{L}$ of cysteine-blocking reagent (AB Sciex Inc.) was added to the sample, followed by incubation at room temperature for $10 \mathrm{~min}$. The reductive alkylated proteins were incubated with sequencing-grade modified trypsin (Promega, Madison, WI) at a ratio of 50:1 (protein:trypsin) at $37^{\circ} \mathrm{C}$ for $16 \mathrm{~h}$.

Digested protein samples were labeled using an iTRAQ 4-plex kit (AB Sciex Inc.) according to the manufacturer's instructions with some modification. Briefly, 1 vial of 4-plex iTRAQ labeling reagent was used for each protein sample. The iTRAQ reagent was solubilized in isopropanol and then added to the protein sample to a final organic concentration of at least $65 \%$ (vol/vol). After $2 \mathrm{~h}$ of iTRAQ labeling, the reaction was quenched by addition of $100 \mu \mathrm{L}$ of deionized water. The samples were then mixed at equal ratios and dried by centrifugal evaporation.

\section{Peptide Fractionation with High pH Reverse-Phase Liquid Chromatography}

After labeling and quenching, the samples were combined and lyophilized. iTRAQ-labeled peptides were fractionated by high $\mathrm{pH}$ reverse-phase chromatography using a Durashell-C18 column $(4.6 \mathrm{~mm} \times 250 \mathrm{~mm}, 5$ $\mu \mathrm{m}, 100$ A; Agela, Wilmington, DE; catalog number: DC952505-0). Dried peptides were reconstituted in 2 $\mathrm{mL}$ of buffer A (see below) and then clarified by centrifugation at $14,000 \times g$ for 20 min before loading onto the column. The flow rate was maintained at $0.7 \mathrm{~mL} /$ min, and the sample was fractionated using a 2-buffer system.

Buffers A and B were prepared as follows: buffer A, 98:2 (deionized water:acetonitrile), $\mathrm{pH}$ 10; buffer $\mathrm{B}$, 2:98 (deionized water:acetonitrile), $\mathrm{pH} 10$. The $\mathrm{pH}$ was adjusted with ammonia. The following gradient was used: $5-8 \%$ buffer B for 5 min, $8-18 \%$ buffer B for 30 min, 18-32\% buffer B for 27 min, 32-95\% buffer B for 2 min, $95 \%$ buffer B for 4 min, $95-5 \%$ buffer B for 4 min, and $5 \%$ buffer B for 10 min. 


\section{Mass Spectrometry Analysis}

According to the UV monitoring results, the separated components were combined into 10 groups using 30 $\mu \mathrm{L}$ of $2 \%$ acetonitrile and $0.1 \%$ formic acid. Then, the fractionated samples were analyzed using nano reversephase liquid chromatography Triple TOF 5600 (AB Sciex Inc.) using a Durashell-C18 column at a flow rate of $2 \mu \mathrm{L} / \mathrm{min}$ for loading and $0.3 \mu \mathrm{L} / \mathrm{min}$ for separation. A binary gradient with solvent A (98\% deionized water, $2 \%$ acetonitrile, and $0.1 \%$ formic acid) and solvent $\mathrm{B}$ ( $2 \%$ deionized water, $98 \%$ acetonitrile, and $0.1 \%$ formic acid) was used as the mobile phase. Separation occurred over 91 min as follows: solvent B was gradually increased from 5 to $10 \%$ for $0.1 \mathrm{~min}, 10$ to $25 \%$ for 59.9 min, 25 to $48 \%$ for $25 \mathrm{~min}, 48$ to $80 \%$ for $1 \mathrm{~min}, 80 \%$ for $4 \mathrm{~min}$, and then decreased from 80 to $5 \%$ for $1 \mathrm{~min}$. Between fractions, $5 \%$ solvent B was maintained for 10 min to equilibrate and clean the column.

The mass spectrometer was operated in positive ion mode with an ion source voltage of 2,300 V using $10-\mu \mathrm{m}$ uncoated SilicaTips (New Objective, Woburn, MA). ProteinPilot 4.0 software (Applied Biosystems/ MDS Sciex, Foster City, CA) was used to collect data in data-dependent acquisition mode for the 3 most intense ions that fulfilled the following criteria: $\mathrm{m} / \mathrm{z}$ between 350 and 1,250; ion intensity of 30 counts; charge state between +2 and +4 . After tandem mass spectroscopic (MS/MS) analysis, the ions were dynamically excluded for $25 \mathrm{~s}$ using a mass tolerance of $50 \mathrm{mDa}$. Mass spectroscopic scans were accumulated for $0.1 \mathrm{~s}$, and MS/MS scans were collected in automatic accumulation mode for $0.25 \mathrm{~s}$. Mass and charge state-dependent rolling collision energy was used, and the mass spectrometer was calibrated daily with $\left[\mathrm{Glu}^{1}\right]$ fibrinopeptide B (Sigma-Aldrich). Instrument cleaning and any necessary maintenance was performed at 24 $\mathrm{h}$ intervals to help control instrument drift. For mass spectroscopic analysis, we used the following search settings: a MS/MS fragment ion mass tolerance of \pm 0.1 Da; threshold at 0.05 Da for ion score; tryptic peptides with $\leq 1$ missed cleavage site; pyrophosphorylation of glutamine, variable oxidation of methionine, and iTRAQ labeling of tyrosine as variable modifications; carbamidomethylation of cysteine and iTRAQ labeling of lysine and the N-terminal amino group of peptides as fixed modifications. Peptide tolerance was set at 20 ppm, and MS/MS tolerance was set at 0.05 Da.

\section{Proteomic Data Analysis}

Peak lists from the MS/MS spectra were prepared using ProteinPilot software version 4.0 (Applied Biosys-
tems/MDS Sciex). The peak list was searched against human proteins using the database HUMAN_20130815 fasta (http://www.uniprot.org). The rationale for using 2 separate algorithms was to reduce false-positive rates for the identified peptides.

\section{Bioinformatics Analysis of Proteins}

For protein-abundance ratios measured using iTRAQ, we set a 1.5-fold change as the threshold and a 2 -tailed $P$-value of $<0.05$ to identify significant changes when compared with the expression of proteins in the untreated HeLa cells. The logic algorithm for set operations was applied to further screen for differentially expressed proteins. Gene ontology functional classifications were analyzed with Blast2GO software (http://www.blast2go.org/). Enrichment analysis was performed to identify gene ontology terms that were significantly enriched for differentially expressed proteins.

\section{RESULTS}

\section{Primary Data Analysis and Differentially Expressed Proteins Identified by ITRAQ}

A total of 206,658 spectra were generated from the iTRAQ experiment using the variously treated HeLa cells. After identification, 18,383 spectra were matched to known spectra and identified as unique peptides; these were in turn identified as 3,244 proteins.

A protein was considered differentially expressed when it had a fold change of $>1.5$ and the change had a $P$-value $<0.05$ compared with untreated cells. Based on these 2 criteria, we identified 112 differentially expressed proteins that responded to $\alpha-\mathrm{LA}-\mathrm{OA}$ treatment. As shown in Figure 1, among the 112 proteins, $95(84.8 \%)$ displayed an increase in expression, and $17(15.2 \%)$ displayed a decrease in expression compared with those in control cells. These proteins were classified using the following categories, according to functional biological properties: nucleic acid metabolism $(42,37.5 \%)$, protein metabolism (11, 9.8\%), lipid metabolism $(6,5.4 \%)$, carbohydrate and energy metabolism $(13,11.6 \%)$, acid metabolism $(2,1.8 \%)$, cell wall and cytoskeleton metabolism $(22,19.6 \%)$, cell transport $(23,20.5 \%)$, stress response $(15,13.4 \%)$, signal transduction $(3,2.7 \%)$, enzyme regulation (4, $3.6 \%$ ), and macromolecule and other biological regulation $(25,22.3 \%)$. Detailed information can be found in Supplemental Table S1 (http://dx.doi.org/10.3168/ jds.2016-10971). 


\section{Proteins Involved in Nucleic Acid Metabolism}

Forty-two proteins involved in nucleic acid metabolism were affected by $\alpha$-LA-OA, including post-transcriptional modification (12), translation (18), RNA (17), DNA (12), and chromosome organization (8) (Table 1). Regulation of RNA includes splicing, processing, stabilization, and metabolic processes; regulation of DNA includes metabolism, ligation, replication, and double-strand break repair. It is worth mentioning that about $88 \%$ of proteins were upregulated (37 of 42 ), indicating an increase in the metabolism of nucleic acids as a result of tumor cell development. However, 5 proteins important for RNA translation (terminal uridylyltransferase 4, TUT4), DNA synthesis (ribonucleotide reductase catalytic subunit, RRM1), DNA repair (Fanconi anemia complementation group I, FANCI), the cell cycle (centromere protein F, CENPF), and inhibition of protein synthesis (ribosomal protein S3a, RPS3A) were downregulated.

\section{Proteins Involved in Protein Metabolism}

Proteins involved in the metabolism of proteins were mainly upregulated (10 of 11 ) in response to $\alpha$-LAOA (Table 2), including the folding (6), binding (2), and maturation (3) of proteins, and the metabolism of amide (1).

\section{Proteins Involved in Carbohydrate and Energy Metabolism}

Tumor cells have a greater need for energy to synthesize macromolecules for duplication, such as nucleotides, proteins, and lipids (Dell'Antone, 2012). The majority of the differentially expressed proteins involved in the metabolism of nucleic acids and proteins were upregulated (Table 1 and Table 2), indicating a need for energy metabolism. In response to $\alpha$-LA-OA, 11 of the 13 differentially expressed proteins involved in carbohydrate and energy metabolism were upregulated

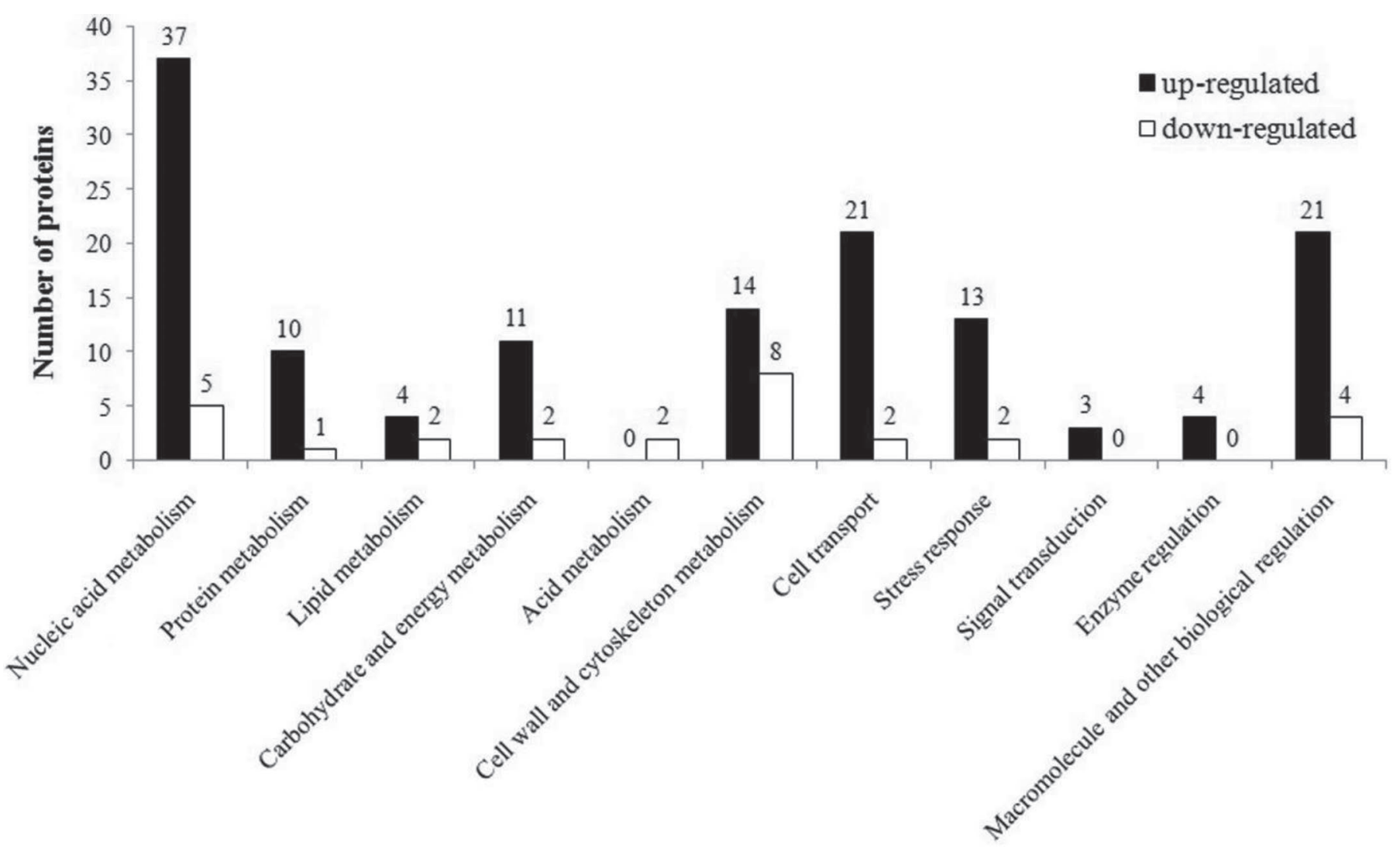

Biological function

Figure 1. Differentially expressed proteins in $\alpha$-lactalbumin-oleic acid-treated HeLa cells compared with control cells. 
Table 1. Differentially expressed proteins that regulate nucleic acid metabolism

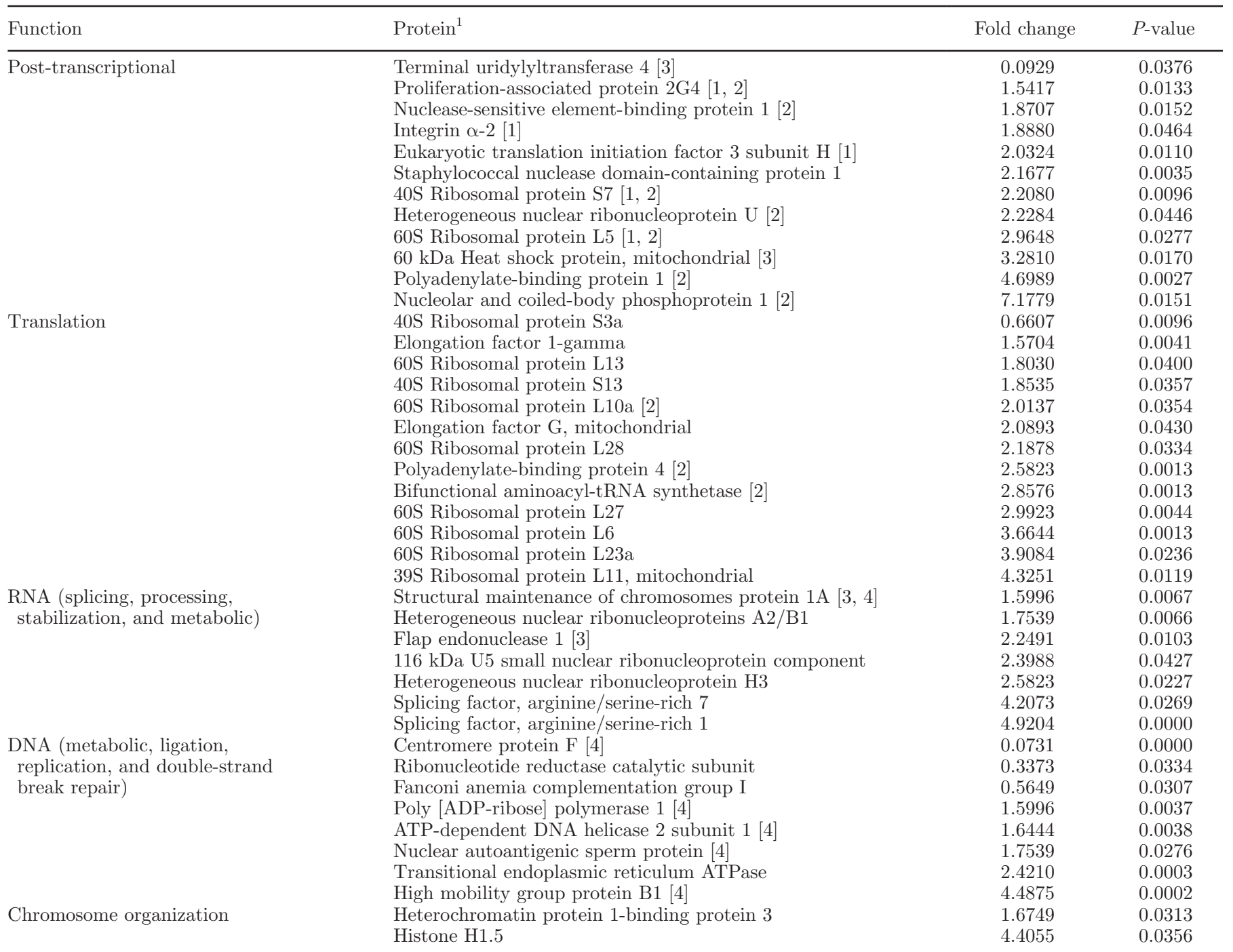

${ }^{1}$ The numbers in brackets beside the names of proteins indicate other functions: 1, 2, 3, and 4 correspond to translation, RNA, DNA, and chromosome organization, respectively.

Table 2. Differentially expressed proteins involved in protein metabolism

\begin{tabular}{llcc}
\hline Function & Protein $^{1}$ & Fold change & $P$-value \\
\hline Folding & T-complex protein 1 subunit epsilon & 1.6144 & 0.0068 \\
& T-complex protein 1 subunit $\beta$ & 1.6596 & 0.0000 \\
& T-complex protein 1 subunit zeta & 1.7539 & 0.0180 \\
& Stress-70 protein, mitochondrial & 2.0512 & 0.0496 \\
& 10 kDa Heat shock protein, mitochondrial & 2.0701 & 0.0346 \\
Binding & 60 kDa Heat shock protein, mitochondrial [5] & 3.2810 & 0.0170 \\
Maturation & Integrin a2 [1, 2] & 1.8880 & 0.0464 \\
& Caldesmon & 1.9588 & 0.0060 \\
Amide metabolic & Poly (ADP-ribose) polymerase 1 [3, 4] & 1.5996 & 0.0037 \\
& SERPINH1 (heat shock protein 47) & 1.6596 & 0.0383 \\
& Huntingtin & 0.1067 & 0.0166
\end{tabular}

${ }^{1}$ The numbers in brackets beside the names of proteins indicate other functions: $1,2,3,4$, and 5 correspond to translation, post-transcriptional, DNA, chromosome organization in nucleic acid metabolism and protein maturation, respectively. 
Table 3. Differentially expressed proteins involved in carbohydrate and energy metabolism

\begin{tabular}{|c|c|c|c|}
\hline Function & Protein $^{1}$ & Fold change & $P$-value \\
\hline \multirow{5}{*}{ Energy metabolism } & Electron transfer flavoprotein subunit $\alpha$, mitochondrial & 1.7701 & 0.0375 \\
\hline & Aconitate hydratase, mitochondrial & 1.8535 & 0.0030 \\
\hline & Electron transfer flavoprotein subunit $\beta$ & 3.0761 & 0.0000 \\
\hline & Protein SCO1 homolog, mitochondrial & 3.1915 & 0.0023 \\
\hline & ATP synthase subunit $\beta$, mitochondrial & 3.4995 & 0.0001 \\
\hline \multirow{4}{*}{ Carbohydrate metabolism } & Glucose-6-phosphate 1-dehydrogenase & 0.5861 & 0.0108 \\
\hline & Fructose-bisphosphate aldolase A [1] & 1.6596 & 0.0028 \\
\hline & Pyruvate kinase isozymes M1/M2 [1] & 1.6749 & 0.0310 \\
\hline & 6-Phosphogluconolactonase & 2.5586 & 0.0321 \\
\hline
\end{tabular}

${ }^{1}$ The number in brackets beside the names of proteins indicates that the protein is also involved in energy metabolism.

(Table 3). Proteins involved in the respiratory electron transport chain, including succinate dehydrogenase, electron transfer flavoprotein (subunits $\alpha$ and $\beta$ ), aconitate hydratase (mitochondrial), $\mathrm{NAD}(\mathrm{P})$ transhydrogenase (mitochondrial), protein SCO1 homolog (mitochondrial), and ATP synthase (subunits $\beta$ and $\mathrm{O}$, mitochondrial), were all upregulated, indicating that Q-LA-OA enhanced respiration in tumor cells. Furthermore, we observed increases in the expression of fructose-bisphosphate aldolase $\mathrm{A}$ and pyruvate kinase isozymes M1/M2, which are also involved in carbohydrate metabolism.

\section{Proteins Involved in Lipid Metabolism}

In addition to striking changes in glucose metabolism in human cancer, free fatty acid turnover, oxidation, and clearance often increase (Liu, 2006). A high demand for ATP can be the result not only of glycolysis but also of the oxidative metabolism of fatty acids (Wolfe, 1998). Six proteins involved in lipid metabolism were expressed differentially in response to $\alpha$-LA-OA, of which 4 regulate the activity of acetyl-CoA that is involved in fatty acid $\beta$-oxidation. The other 2 proteins are involved in biosynthesis of cholesterol and sterol (Table 4).

\section{Proteins Involved in Lactate Metabolism}

Normal tissues do not generally convert glucose to lactic acid, except under hypoxic conditions. Accumulation of lactate in solid tumors is a pivotal and early event in the development of malignancies (Hirschhaeuser et al., 2011). When the cells were treated with $\alpha$-LA-OA, proteins involved in lactate metabolism were downregulated significantly (Table 5).

\section{Proteins Involved in Cell Wall and Cytoskeleton}

As shown in Table 6, 22 proteins involved in the cell wall and cytoskeleton were expressed differentially, including proteins regulating membrane organization (8), cellular component organization (8), and development of the epidermis and ectoderm (3).

\section{Proteins Involved in Endoplasmic Reticulum-Nuclear Signaling Pathway}

As shown in Table 7, differentially expressed proteins involved in the endoplasmic reticulum (ER)-nuclear signaling pathway were upregulated. The HAMLET complex is partially resistant to proteasomal degradation (Gustafsson et al., 2009), leading to ER stress and the unfolded protein response (Lee et al., 2003).

Table 4. Differentially expressed proteins involved in lipid metabolism

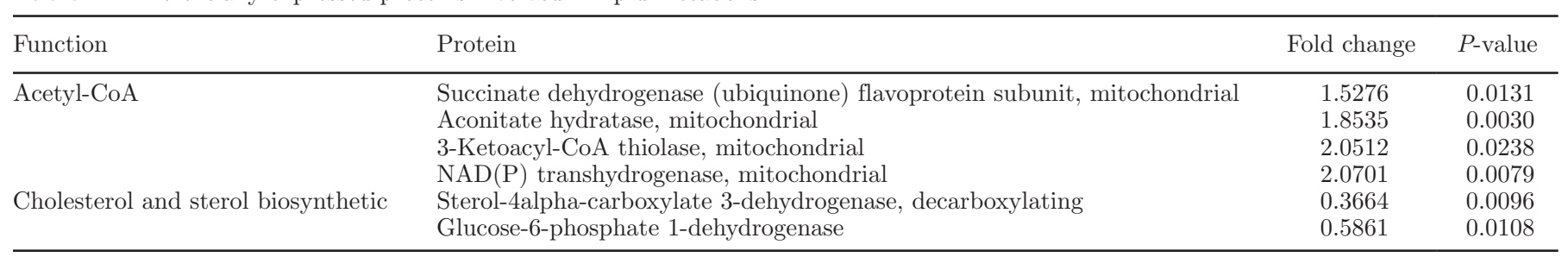


Table 5. Differentially expressed proteins involved in lactate metabolism

\begin{tabular}{llc}
\hline Function & Protein & Fold change \\
\hline Lactate metabolism & Huntingtin & 0.1067 \\
& 6-Phosphofructo-2-kinase/fructose-2,6-biphosphatase 2 & 0.0166 \\
\hline
\end{tabular}

Table 6. Differentially expressed proteins that regulate the cell wall and cytoskeleton

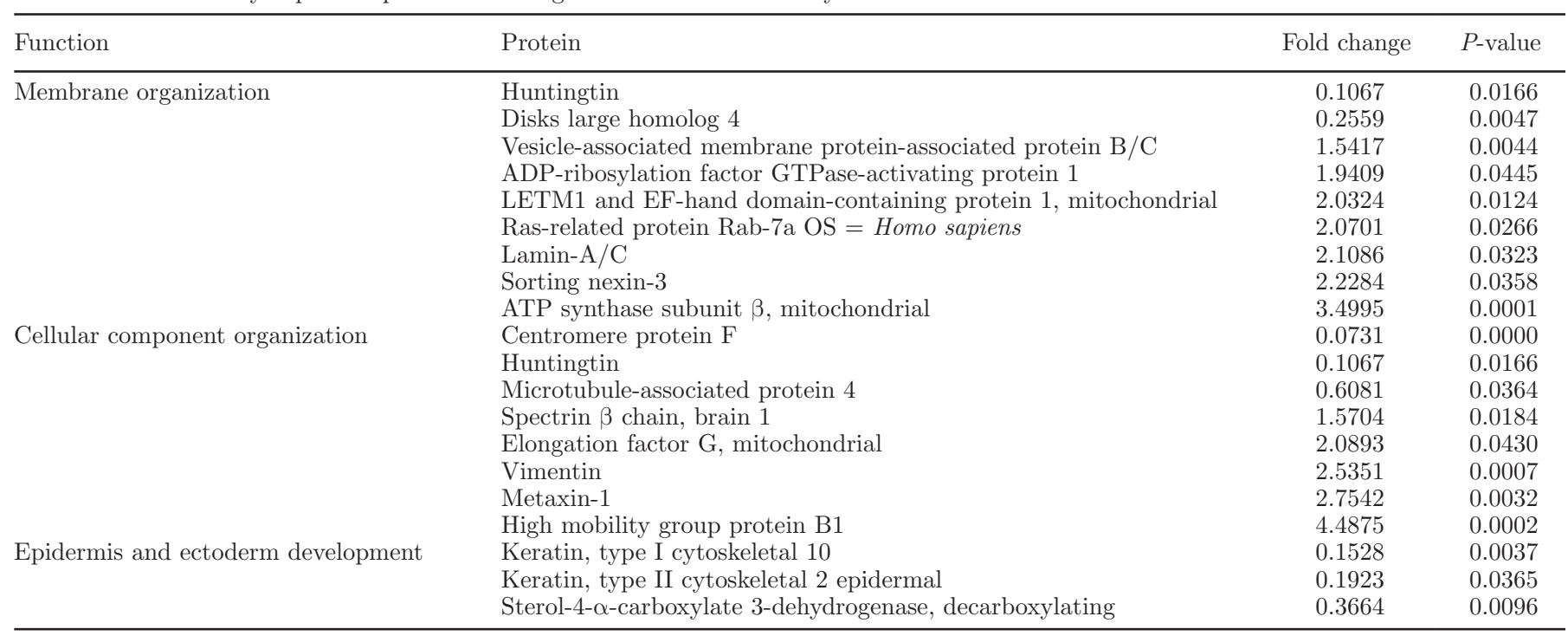

Table 7. Differentially expressed proteins involved in the endoplasmic reticulum-nuclear signaling pathway

\begin{tabular}{|c|c|c|c|}
\hline Function & Protein & Fold change & $P$-value \\
\hline $\begin{array}{l}\text { Endoplasmic reticulum-nuclear signaling } \\
\text { pathway }\end{array}$ & Transitional endoplasmic reticulum ATPase & 2.4210 & 0.0003 \\
\hline
\end{tabular}

Table 8. Differentially expressed proteins involved in stress responses

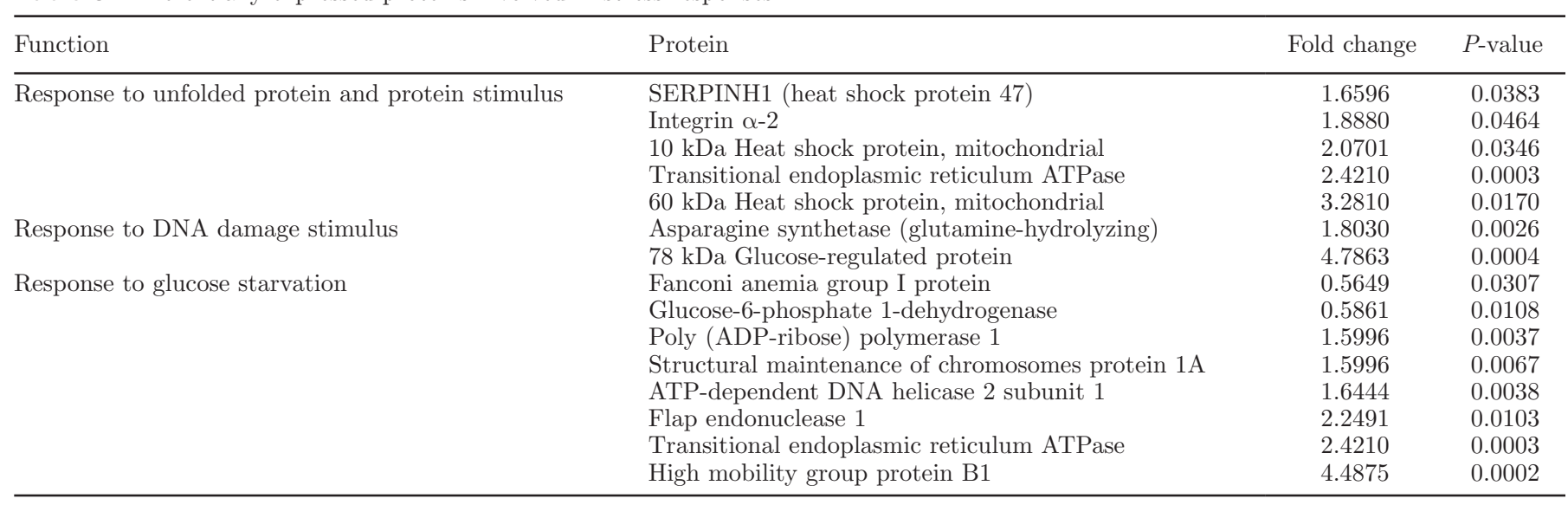




\section{Proteins Involved in Stress Response}

After $\alpha$-LA-OA treatment, the expression of 15 proteins involved in the stress response were differentially regulated (Table 8). A series of heat shock proteins (Hsp47, Hsp10, and Hsp60) were upregulated; these proteins are upregulated when cells are exposed to stress such as the unfolded protein response (De Maio, 1999). Furthermore, heat shock proteins can regulate the activity of caspases, endopeptidases, and peptidases, leading to activation of apoptosis (Wang and Lenardo, 2000).

\section{DISCUSSION}

\section{Proteins Involved in Nucleic Acid Metabolism}

The proteins TUT4, RRM1, FANCI, CENPF, and RPS3a were downregulated in response to $\alpha$-LA-OA (Table 1). The TUT4 protein catalyzes the chemical reaction of uridine triphosphate for RNA transcription (Heo et al., 2009). Downregulation of TUT4 may inhibit the synthesis of RNA during transcription by limiting the reaction of the substrate (Thornton et al., 2012).

The protein RRM1 is a major component of ribonucleoside-diphosphate reductase, a rate-limiting enzyme in DNA synthesis (Parker et al., 1995). It is highly expressed in tumor cells, especially in lung and pancreatic cancers (Davidson et al., 2004; Metro et al., 2010). It has been reported that patients with low RRM1 expression benefit from gemcitabine/carboplatin chemotherapy (Zhang et al., 2012). Downregulation of RRM1 indicates that it might be a target of $\alpha$-LA-OA to limit DNA synthesis. Furthermore, hydroxyurea, a clinically useful antitumor agent, has been shown to target ribonucleotide reductase (Navarra and Preziosi, 1999).

The function of FANCI, which belongs to the Fanconi anemia protein family, remains uncharacterized at the molecular level (Levitus et al., 2004). Fanconi anemia is caused by mutations in genes controlling DNA inter-strand crosslink repair. Cells from people with Fanconi anemia are sensitive to antitumor drugs that target DNA cross-linking, such as mitomycin C (Alter et al., 2003). The FANCI protein was identified as the second mono-ubiquitinated member of the Fanconi anemia pathway (Sims et al., 2007) and as an ATM/ ATR kinase substrate required for resistance against mitomycin C (Smogorzewska et al., 2007).

The CENPF protein, also known as mitosin, is a nuclear protein involved in centromere formation and kinetochore organization during mitosis (Rattner et al., 1993). It was initially identified as an autoimmune antigen (Ma et al., 2006), and its expression is upregulated in cancer cells (Welner et al., 2013). Fur- thermore, CENPF is a useful proliferation marker in cancer research because of its dynamic localization and expression during mitosis. The CENPF protein is undetectable or weakly expressed in the $\mathrm{G}_{1}$ phase of the cell cycle and then undergoes upregulation when cells are released from early $\mathrm{G}_{1}$, suggesting a correlation with $\mathrm{S}$ phase entry. The high expression level of CENPF then persists until anaphase. At the end of mitosis, it is degraded rapidly (Ma et al., 2006; Zhou et al., 2005). The cycle of HeLa cells treated with $\alpha$-LA-OA exhibited arrest in the $\mathrm{G}_{1}$ phase (Supplemental Figure S1; http://dx.doi.org/10.3168/jds.2016-10971).

The RPS3a protein belongs to the S3AE family of ribosomal proteins, which catalyzes protein synthesis (Nolte et al., 1996). Early studies indicated that RPS3a expression is generally higher in most tumor cells than in normal cells, and apoptosis can be induced by inhibition of RPS3a expression (Naora et al., 1998; Shenoy et al., 2012). The $\alpha$-LA-OA-treated cells show significant apoptotic characters (Fang et al., 2012; 2014). Downregulation of RPS3a may lead to a reduction in the levels of survival/protective factors (Naora et al., 1998; Steller, 1995), substantially triggering apoptosis. Furthermore, several studies have favored the involvement of $\alpha$-LA-OA in nucleic acid metabolism, including the accumulation in the cell nucleus (Håkansson et al., 1995, 1999) and interaction with histones and chromatin in tumor cell nuclei (Düringer et al. 2003).

\section{Proteins Involved in Protein Metabolism}

Because $\alpha$-LA-OA is a protein, changes in protein metabolism in HeLa cells may be related to its antitumor activity. T-complex protein 1 (TCP1) and mitochondrial heat shock protein were upregulated, and these belong to the chaperonin family. Chaperonins assist protein folding upon ATP hydrolysis (Kubota et al., 1994). The increased expression of these 2 chaperonins indicates acceleration of protein folding. It has been reported that misfolding of proteins may lead to the development of diseases such as cancer (Nagaraj et al., 2010).

Integrin $\alpha 2$, also called CD49b, belongs to the integrin family. It binds to extracellular matrix proteins, acts as a receptor for cell surface adhesion molecules, and is involved in cell adhesion and cell-cell interactions (Hynes, 1992). Upregulation of integrin a 2 may be due to the metastasis of tumor cells to facilitate metastatic functions (Hood and Cheresh, 2002; Yilmaz and Christofori, 2009).

Caldesmon is a calmodulin-binding protein with the ability to transduce calcium signals by binding calcium ions and then modifying its interactions with various target proteins (Chin and Means, 2000). Upregulation 
of caldesmon expression is thought to be a useful marker for smooth muscle, myofibroblastic, and colorectal tumors (Ceballos et al., 2000; Kim et al., 2012).

The only downregulated protein, huntingtin, is related to Huntington's disease, an autosomal dominant genetic disorder (Ross and Tabrizi, 2011). Huntingtin is essential for development, and its absence in mice is reported to be lethal to embryos (Nasir et al., 1995). Furthermore, huntingtin is associated primarily with vesicles and microtubules (DiFiglia et al., 1995; Hoffner et al., 2002), indicating an involvement in cytoskeletal anchoring or transport of mitochondria. Huntingtin also interacts with HIP1, a clathrin-binding protein, to mediate endocytosis (Velier et al., 1998; Waelter et al., 2001). The downregulation of huntingtin induced by $\alpha$-LA-OA indicates that it is a potential target for cancer therapy.

\section{Proteins Involved in Carbohydrate and Energy Metabolism}

Many tumor cells display high rates of aerobic glycolysis to support continuous cell growth and proliferation in a challenging environment, a phenomenon known as the Warburg effect (Ros and Schulze, 2013). Here, we found upregulation of fructose-bisphosphate aldolase A, pyruvate kinase isozymes M1/M2, and 6-phosphogluconolactonase in response to $\alpha$-LA-OA, all of which are involved in carbohydrate metabolism, indicating increased glycolytic capacity (Table 3). Fructose-bisphosphate aldolase $\mathrm{A}$ is an enzyme that reversibly catalyzes fructose 1,6 -bisphosphate, which is presumably involved in gluconeogenesis (Estelmann et al., 2011). Pyruvate kinase isozymes M1/M2 are isoenzymes of the glycolytic enzyme pyruvate kinase, which are expressed in all cells with a high rate of nucleic acid synthesis, especially tumor cells (Brinck et al., 1994). 6-Phosphogluconolactonase is involved in the pentose phosphate pathway and converts 6-phosphogluconolactone to 6-phosphogluconate, an intermediate to produce ribulose 5-phosphate by phosphogluconate dehydrogenase. However, we found significant downregulation of 6-phosphofructo-2-kinase/fructose-2,6-biphosphatase 2 (PFKFB2) and glucose-6-phosphate 1-dehydrogenase (G6PD), 2 key proteins involved in the pentose phosphate pathway.

The PFKFB2 protein belongs to the 6-phosphofructo-2-kinase/fructose-2,6-biphosphatase (PFKFB) family, which catalyzes the synthesis and degradation of fructose 2,6-bisphosphate, the most potent activator of glycolysis (Okar and Lange, 1999; Rider et al., 2004). Regulation of glycolysis allows tumor cells to fulfill their bioenergetic and biosynthetic demands, and disruption of this balance is likely to limit the capacity of cancer cells to adapt to metabolic constraints (Yalcin et al., 2009; Ros and Schulze, 2013). Downregulation of PFKFB2 induced by $\alpha$-LA-OA leads to energy constraint in tumor cells, indicating its antitumor mechanism and making PFKFB2 an attractive target for cancer therapy (Clem et al., 2008; Yalcin et al., 2009).

The G6PD protein is the rate-limiting enzyme in the pentose phosphate pathway for maintaining the level of NADP, which in turn maintains the sulfhydryl groups of cellular proteins and aids in detoxification of free radicals and peroxides (Kuo et al., 2000; Tian et al., 1998). In addition to maintaining NADP, the reaction of G6PD in the pentose phosphate pathway produces 5 -ribose phosphate, a precursor of nucleic acids. G6PD may act as a potential oncogene, the overexpression of which plays a critical role in tumor genesis (Kuo et al., 2000; Ohl et al., 2005, 2006). A decrease in the expression of G6PD indicates that $\alpha$-LA-OA may induce inhibition of uncontrollable cell proliferation in tumor cells (Li et al., 2009).

Several proteins involved in energy and carbohydrate metabolism are upregulated in tumor cells to ensure sufficient supply of ATP. However, we found downregulation of PFKFB2 and G6PD, the most important proteins in glycolysis and the pentose phosphate pathway. It has been reported that depletion of glucose or addition of 2-deoxyglucose, a glycolysis inhibitor, significantly increases the sensitivity of tumor cells to HAMLET (Storm et al., 2011), in accordance with our results.

\section{Proteins Involved in Lipid Metabolism}

Acceleration of cholesterol and lipid metabolism (Table 4) is a hallmark of cancer and contributes to malignant transformation (Gabitova et al., 2014). Lipid biogenesis has become an attractive biochemical target in cancer therapy because of the requirement for cholesterol and the high dependency on sterols in cellular membranes (Gorin et al., 2012; Gabitova et al., 2014). Treatment with $\alpha$-LA-OA decreased expression of sterol-4alpha-carboxylate 3-dehydrogenase (decarboxylating) and G6PD, leading to a decrease in the content of cholesterol and sterol. Moreover, a decrease in proteins regulating acetyl-CoA may lead to $\beta$-oxidation or degradation of existing lipids, enhancing the insufficiency of lipids.

\section{Proteins Involved in Lactate Metabolism}

Proteins involved in lactate metabolism were significantly downregulated in cells treated with $\alpha$-LAOA (Table 5). Normal tissues do not generally convert glucose to lactic acid except under hypoxic conditions. 
In contrast, accumulation of lactate in solid tumors is a pivotal and early event in the development of malignancies (Liu, 2006). Tumors are characterized by converting most glucose into lactic acid, sacrificing energy availability even in the presence of oxygen. Furthermore, it has been reported that the concentration of lactate is positively correlated with radio-resistance (Sattler et al., 2010), and lactate has been a target of cancer therapeutics (Doherty and Cleveland, 2013). As shown in Table 5, the downregulation of huntingtin and PFKFB2 led not only to disruption of glycolysis and protein metabolism, respectively, but also to a decrease in the concentration of lactate.

\section{Proteins Involved in Cell Wall and Cytoskeleton}

The metastatic process and spread of tumor cells require them to detach from the primary tumor and acquire migratory and invasive capabilities (Hood and Cheresh, 2002). This process, called epithelialmesenchymal transition (Grunert et al., 2003; Thiery and Sleeman, 2006), requires the involvement of cytoskeleton proteins and is critically associated with tumor progression (Grunert et al., 2003; Thiery and Sleeman, 2006; Kong et al., 2011). In response to $\alpha$-LA-OA, we found upregulation of proteins associated with vesicular trafficking and actin remodeling, such as vesicleassociated membrane protein-associated protein B/C, ADP-ribosylation factor GTPase-activating protein 1, and Ras-related protein Rab-7a. Concurrently, we found upregulation of all proteins comprising the cytoskeleton, including vimentin, metaxin- 1 , spectrin $\beta$ chain, brain 1, and high mobility group protein B1. However, we identified downregulation of the critical microtubule-associated protein 4 that regulates the stability of the cytoskeleton (Permana et al., 2005). A decrease in the expression of microtubule-associated protein 4 resulted in the instability of the cytoskeleton. We also found downregulation of keratins that are recognized as protectors of epithelial structural integrity under stress conditions and as regulators of motility, signaling, growth, and other cellular functions (Karantza, 2011). Keratins are commonly used as diagnostic markers in tumor pathology (Karantza, 2011). Keratin 2 and 10 were downregulated by $\alpha-\mathrm{LA}-\mathrm{OA}$, indicating inhibition of the development of metastasis in HeLa cells.

In addition to proteins, cholesterol and phospholipid are also components of the cell membrane (Simons and

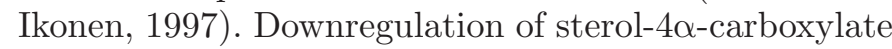
3-dehydrogenase (decarboxylating) destroys the structure of the cell membrane. The cytoskeleton and cell membrane constitute a barrier between the interior of the cell and the outer environment (Simons and Ikonen,
1997), which controls the movement of substances in and out of cells (Mansy, 2010).

Furthermore, disks large homolog 4 has been reported to regulate clustering of receptors, ion channels, and their associated signaling proteins (Entrez data; http://www.ncbi.nlm.nih.gov/gene/1742). The downregulation of protein expression induced by $\alpha-\mathrm{LA}-\mathrm{OA}$ resulted in dysfunction of the cell membrane, including transportation of ions and signal transduction. It has also been reported that exposure of tumor cells to HAMLET activates ion channels and induces rapid efflux of potassium and influx of calcium and sodium (Storm 2012). Other studies also reported that $\alpha$-LAOA destroyed the function and structure of the cell membrane. The $\alpha$-LA-OA complex was reported to irreversibly bind to the plasmalemma, accompanied by an increase in nonspecific potassium ion leakage currents, reflecting the development of nonselective permeability of the plasma membrane (Storm 2012). Zherelova et al. (2009) found that $\alpha$-LA-OA accumulated in membranes of vesicles and disrupted membrane integrity at neutral $\mathrm{pH}$ and physiological conditions, resulting in increased membrane fluidity as shown by fluorophore leakage experiments. Mossberg et al. (2010b), found that $\alpha$-LA-OA incorporated into the membrane, tightened the lipid packing, and lowered its accessibility. Fluorescence imaging revealed the bleb of the giant unilamellar vesicles, which eventually collapsed upon exposure to $\alpha$-LA-OA, indicating the observable morphological effects induced by the lipid packing reorganization of $\alpha$-LA-OA (Mossberg et al., 2010b). When we studied the internalization property of $\alpha-\mathrm{LA}-\mathrm{OA}$ in HeLa cells (Supplemental Figure S2; http://dx.doi. org/10.3168/jds.2016-10971), it was found that during the transporting of $\alpha-\mathrm{LA}-\mathrm{OA}$, cells began to shrink to circular and the adhesion of cells began to decrease as well, indicating the damage to cell cytoskeleton.

\section{Proteins Involved in Endoplasmic Reticulum-Nuclear Signaling Pathway}

Endoplasmic reticulum is a cellular compartment for protein folding and assembly (Gething and Sambrook, 1992). During tumorigenesis, the high proliferation rate of tumor cells requires an increase in ER activities for protein folding, assembly, and transport (Martinon, 2012). As the tumor grows, altered glycosylation, increasing nutrient starvation, oxidative stress, DNA damage, or energy perturbation/fluctuations can result in the accumulation of unfolded or misfolded proteins in the ER, a condition referred to as "ER stress" (Kadowaki and Nishitoh, 2013; Wang et al., 2010, 2014).

Transitional endoplasmic reticulum ATPase, also called valosin-containing protein, associates with clath- 
rin and heat shock protein 70 to form a complex that regulates membrane fusion and ubiquitin-dependent protein degradation (Zhang et al., 2000; Jiang et al., 2013). Moreover, transitional endoplasmic reticulum ATPase is involved in autophagy and the function of the $26 \mathrm{~S}$ proteasome (Jiang et al., 2013). The HAMLET complex triggers autophagy in tumor cells (Aits et al., 2009), supported by upregulation of transitional endoplasmic reticulum ATPase.

The $78-\mathrm{kDa}$ glucose-regulated protein (GRP78), also known as binding immunoglobulin protein and heat shock $70-\mathrm{kDa}$ protein 5 , functions as a sensor of ER stress (Martin et al., 2013). The GRP78 protein is located in the ER lumen and binds newly synthesized proteins that are translocated into the ER for subsequent folding and oligomerization (Entrez data; http://www.ncbi.nlm.nih.gov/gene/415113). Early studies have reported that HAMLET interacts directly with ER stress sensors (Storm, 2012), and molecules that bind to GRP78 can induce apoptosis in response to ER stress (Zhou et al., 2011; Martin et al., 2013). Upregulation of GRP78 explains the apoptosis and autophagy induced by $\alpha-\mathrm{LA}-\mathrm{OA}$, and GRP78 may be an important target of $\alpha$-LA-OA.

\section{Proteins Involved in Stress Response}

Tumor cells treated with HAMLET or its analogs exhibit characters of apoptosis, including activation of caspases (Hallgren et al., 2006; Shenoy et al., 2012). Upregulation of heat shock proteins induced by $\alpha-L A-$ OA may be the first stimulator of apoptosis, which can explain why apoptosis is still activated by $\alpha-\mathrm{LA}-\mathrm{OA}$ in the presence of caspase inhibitors (Hallgren et al., 2006).

Integrins govern the adhesion and shape of cells, and are critical factors in the cellular responses to survival factors (Stupack and Cheresh, 2002). Integrin $\alpha 2$ binds to extracellular matrix proteins, collagens, and laminins, which are receptors for cell surface adhesion molecules (Meredith et al., 1993). Upregulation of integrin $\alpha 2$ by $\alpha$-LA-OA may increase the cellular response to stress. Poly (ADP-ribose) polymerase 1 (PPAP1) is involved in many aspects of responses to cellular damage such as DNA damage (Kim et al., 2012). DNA fragments have been found in cells treated with HAMLET-like complexes (Håkansson et al., 1999; Svensson et al., 2000; Fontana et al., 2013), indicating DNA damage. Upregulation of PPAP1 may be due to the response to DNA damage induced by $\alpha-\mathrm{LA}-\mathrm{OA}$. Furthermore, as shown in Table 3, we identified significant downregulation of PFKFB2 and G6PD, 2 key proteins involved in the pentose phosphate pathway. The induction of an insufficient energy supply resulted in cellular responses to glucose starvation (Table 8). Based on our results, FANCI and G6PD were involved in cellular stress response pathways and their downregulation may lead to tumor cell death.

\section{CONCLUSIONS}

In $\alpha$-LA-OA-treated cells, we identified 95 upregulated and 17 downregulated proteins (significant fold change $>1.5$ ). The upregulated proteins were correlated with a greater need to satisfy the progression of tumor cells by enhancing the synthesis and maturation of nucleic acids, proteins, and energy. The downregulated proteins may contribute to tumor cell death. The mechanism of the antitumor activity of $\alpha$-LA-OA might include the following aspects: (1) disruption of cytoskeleton stability, cell motility, and signal transduction; (2) insufficient supply of ATP; (3) limiting the rate of DNA synthesis; (4) disruption of mitosis; (5) expression of tumor suppressors; (6) acceleration of protein metabolism induced by ER stress; and (7) activation of programmed cell death. The antitumor mechanism of $\alpha-\mathrm{LA}-\mathrm{OA}$ is influenced by a series of metabolites and proteins in the cell, forming a complicated network.

\section{ACKNOWLEDGMENTS}

We gratefully acknowledge financial support from the Beijing Science and Technology Project (D141100004814001), the Ministry of Science and Technology of China (2012BAD12B08), and the Beijing Municipal Commission of Education Co-constructed Program. We thank Songling Liu and Mai Tian (College of Food Science and Nutritional Engineering, China Agricultural University, Beijing, China) for their technical assistance.

\section{REFERENCES}

Aits, S., L. Gustafsson, O. Hallgren, P. Brest, M. Gustafsson, M. Trulsson, A. K. Mossberg, H. U. Simon, B. Mograbi, and C. Svanborg. 2009. HAMLET (human $\alpha$-lactalbumin made lethal to tumor cells) triggers autophagic tumor cell death. Int. J. Cancer 124:1008-1019.

Alter, B. P., M. H. Greene, I. Velazquez, and P. S. Rosenberg. 2003. Cancer in Fanconi anemia. Blood 101:2072.

Brinck, U., E. Eigenbrodt, M. Oehmke, S. Mazurek, and G. Fischer. 1994. L- and M2-pyruvate kinase expression in renal cell carcinomas and their metastases. Virchows Arch. 424:177-185.

Carlsson, N., A. Borde, S. Wölfel, B. Kerman, and A. Larsson. 2011. Quantification of protein concentration by the Bradford method in the presence of pharmaceutical polymers. Anal. Biochem. 411:116121.

Ceballos, K. M., G. P. Nielsen, M. K. Selig, and J. X. O'Connell. 2000. Is anti-h-caldesmon useful for distinguishing smooth muscle and myofibroblastic tumors? An immunohistochemical study. Am. J. Clin. Pathol. 114:746-753.

Chin, D., and A. R. Means. 2000. Calmodulin: A prototypical calcium sensor. Trends Cell Biol. 10:322-328. 
Clem, B., S. Telang, A. Clem, A. Yalcin, J. Meier, A. Simmons, M. A. Rasku, S. Arumugam, W. L. Dean, J. Eaton, A. Lane, J. O. Trent, and J. Chesney. 2008. Small-molecule inhibition of 6-phosphofructo-2-kinase activity suppresses glycolytic flux and tumor growth. Mol. Cancer Ther. 7:110-120.

Davidson, J. D., L. Ma, M. Flagella, S. Geeganage, L. M. Gelbert, and C. A. Slapak. 2004. An increase in the expression of ribonucleotide reductase large subunit 1 is associated with gemcitabine resistance in non-small cell lung cancer cell lines. Cancer Res. 64:3761-3766.

De Maio, A. 1999. Heat shock proteins: Facts, thoughts, and dreams. Shock 11:1-12.

Dell'Antone, P. 2012. Energy metabolism in cancer cells: how to explain the Warburg and Crabtree effects? Med. Hypotheses 79:388392.

DiFiglia, M., E. Sapp, K. Chase, C. Schwarz, A. Meloni, C. Young, E. Martin, J. P. Vonsattel, R. Carraway, and S. A. Reeves. 1995. Huntingtin is a cytoplasmic protein associated with vesicles in human and rat brain neurons. Neuron 14:1075-1081.

Doherty, J. R., and J. L. Cleveland. 2013. Targeting lactate metabolism for cancer therapeutics. J. Clin. Invest. 123:3685-3692.

Düringer, C., A. Hamiche, L. Gustafsson, H. Kimura, and C. Svanborg. 2003. HAMLET interacts with histones and chromatin in tumor cell nuclei. J. Biol. Chem. 278:42131-42135.

Estelmann, S., M. Hügler, W. Eisenreich, K. Werner, I. A. Berg, W H. Ramos-Vera, R. F. Say, D. Kockelkorn, N. Gad'on, and G. Fuchs. 2011. Labeling and enzyme studies of the central carbon metabolism in Metallosphaera sedula. J. Bacteriol. 193:1191-1200.

Fang, B., M. Zhang, L. Jiang, H. Jing, and F. Z. Ren. 2012. Influence of $\mathrm{pH}$ on the structure and oleic acid binding ability of bovine Q-lactalbumin. Protein J. 31:564-572.

Fang, B., M. Zhang, M. Tian, L. Jiang, H. Y. Guo, and F. Z. Ren 2014. Bovine lactoferrin binds oleic acid to form an antitumor complex similar to HAMLET. Biochim. Biophys. Acta 1841:535-543.

Fang, B., M. Zhang, M. Tian, and F. Z. Ren. 2015. Self-assembled $\beta$-lactoglobulin-oleic acid and $\beta$-lactoglobulin-linoleic acid complexes with antitumor activities. J. Dairy Sci. 98:2898-2907.

Fischer, W., L. Gustafsson, A. K. Mossberg, J. Gronli, S. Mork, R. Bjerkvig, and C. Svanborg. 2004. Human $\alpha$-lactalbumin made lethal to tumor cells (HAMLET) kills human glioblastoma cells in brain xenografts by an apoptosis-like mechanism and prolongs survival. Cancer Res. 64:2105-2112.

Fontana, A., B Spolaore, and P. Polverino de Laureto. 2013. The biological activities of protein/oleic acid complexes reside in the fatty acid. Biochim. Biophys. Acta 1834:1125-1143.

Fukao, Y., A. Ferjani, R. Tomioka, N. Nagasaki, R. Kurata, Y. Nishimori, M. Fujiwara, and M. Maeshima. 2011. iTRAQ analysis reveals mechanisms of growth defects due to excess zinc in Arabidopsis. Plant Physiol. 155:1893-1907.

Gabitova, L., A. Gorin, and I. Astsaturov. 2014. Molecular pathways: sterols and receptor signaling in cancer. Clin. Cancer Res. 20:28 34 .

Gething, M. J., and J. Sambrook. 1992. Protein folding in the cell Nature 355:33-45.

Ghochani, B. F. N. M., and K. Gilany. 2011. Proteomics a key tool for a better understanding of endometriosis: A mini-review. J. Paramed. Sci. 2:51-58

Gorin, A., L. Gabitova, and I. Astsaturov. 2012. Regulation of cholesterol biosynthesis and cancer signaling. Curr. Opin. Pharmacol. 12:710-716.

Grünert, S., M. Jechlinger, and H. Beug. 2003. Diverse cellular and molecular mechanisms contribute to epithelial plasticity and metastasis. Nat. Rev. Mol. Cell Biol. 4:657-665.

Gustafsson, L., S. Aits, P. Onnerfjord, M. Trulsson, P. Storm, and C. Svanborg. 2009. Changes in proteasome structure and function caused by HAMLET in tumor cells. PLoS ONE 4:e5229.

Gustafsson, L., I. Leijonhufvud, A. Aronsson, A. K. Mossberg, and C. Svanborg. 2004. Treatment of skin papillomas with topical alphalactalbumin-oleic acid. N. Engl. J. Med. 350:2663-2672.

Håkansson, A., J. Andréasson, B. Zhivotovsky, D. Karpman, S. Orrenius, and C. Svanborg. 1999. Multimeric alpha-lactalbumin from human milk induces apoptosis through a direct effect on cell nuclei. Exp. Cell Res. 246:451-460.

Håkansson, A., B. Zhivotovsky, S. Orrenius, H. Sabharwal, and C. Svanborg. 1995. Apoptosis induced by a human milk protein. Proc. Natl. Acad. Sci. USA 92:8064-8068.

Hallgren, O., L. Gustafsson, H. Irjala, G. Selivanova, S. Orrenius, and C. Svanborg. 2006. HAMLET triggers apoptosis but tumor cell death is independent of caspases, Bcl-2 and p53. Apoptosis $11: 221-233$

Heo, I., C. Joo, Y. K. Kim, M. Ha, M. J. Yoon, J. Cho, K. H. Yeom, J. Han, and V. N. Kim. 2009. TUT4 in concert with Lin28 suppresses microRNA biogenesis through pre-microRNA uridylation. Cell 138:696-708.

Hirschhaeuser, F., U. G. Sattler, and W. Mueller-Klieser. 2011. Lactate: A metabolic key player in cancer. Cancer Res. 71:6921-6925.

Hoffner, G., P. Kahlem, and P. Djian. 2002. Perinuclear localization of huntingtin as a consequence of its binding to microtubules through an interaction with beta-tubulin: Relevance to Huntington's disease. J. Cell Sci. 115:941-948.

Hood, J. D., and D. A. Cheresh. 2002. Role of integrins in cell invasion and migration. Nat. Rev. Cancer 2:91-100.

Hynes, R. O. 1992. Integrins: Versatility, modulation, and signaling in cell adhesion. Cell 69:11-25.

Jiang, N., Y. Shen, X. Fei, K. Sheng, P. Sun, Y. Qiu, J. Larner, L. Cao, X. Kong, and J. Mi. 2013. Valosin-containing protein regulates the proteasome-mediated degradation of DNA-PKcs in glioma cells. Cell Death Dis. 4:e647.

Kadowaki, H., and H. Nishitoh. 2013. Signaling pathways from the endoplasmic reticulum and their roles in disease. Genes (Basel) 4:306-333.

Karantza, V. 2011. Keratins in health and cancer: More than mere epithelial cell markers. Oncogene 30:127-138

Kim, K. H., S. G. Yeo, W. K. Kim, D. Y. Kim, H. Y. Yeo, J. P. Hong, H. J. Chang, J. W. Park, S. Y. Kim, B. C. Kim, and B. C. Yoo. 2012. Up-regulated expression of l-caldesmon associated with malignancy of colorectal cancer. BMC Cancer 12:601.

Kong, D., Y. Li, Z. Wang, and F. H. Sarkar. 2011. Cancer stem cells and epithelial-to-mesenchymal transition (EMT)-phenotypic cells: Are they cousins or twins? Cancers (Basel) 3:716-729.

Kubota, H., G. Hynes, A. Carne, A. Ashworth, and K. Willison. 1994 Identification of six Tcp-1-related genes encoding divergent subunits of the TCP-1-containing chaperonin. Curr. Biol. 4:89-99.

Kuo, W., J. Lin, and T. K. Tang. 2000. Human glucose-6-phosphate dehydrogenase (G6PD) gene transforms NIH 3T3 cells and induces tumors in nude mice. Int. J. Cancer 85:857-864.

Lee, A. H., N. N. Iwakoshi, K. C. Anderson, and L. H. Glimcher. 2003. Proteasome inhibitors disrupt the unfolded protein response in myeloma cells. Proc. Natl. Acad. Sci. USA 100:9946-9951.

Levitus, M., M. A. Rooimans, J. Steltenpool, N. F. Cool, A. B. Oostra, C. G. Mathew, M. E. Hoatlin, Q. Waisfisz, F. Arwert, J. P. De Winter, and H. Joenje. 2004. Heterogeneity in Fanconi anemia: evidence for 2 new genetic subtypes. Blood 103:2498-2503.

Li, D., Y. Zhu, Q. Tang, H. Lu, H. Li, Y. Yang, Z. Li, and S. Tong. 2009. A new G6PD knockdown tumor-cell line with reduced proliferation and increased susceptibility to oxidative stress. Cancer Biother. Radiopharm. 24:81-90.

Liu, Y. 2006. Fatty acid oxidation is a dominant bioenergetic pathway in prostate cancer. Prostate Cancer Prostatic Dis. 9:230-234.

Ma, L., X. Zhao, and X. Zhu. 2006. Mitosin/CENP-F in mitosis, transcriptional control, and differentiation. J. Biomed. Sci. 13:205-213.

Mansy, S. S. 2010. Membrane transport in primitive cells. Cold Spring Harb. Perspect. Biol. 2:a002188.

Martin, S., H. K. Lamb, C. Brady, B. Lefkove, M. Y. Bonner, P. Thompson, P. E. Lovat, J. L. Arbiser, A. R. Hawkins, and C. P. Redfern. 2013. Inducing apoptosis of cancer cells using smallmolecule plant compounds that bind to GRP78. Br. J. Cancer 109:433-443.

Martinon, F. 2012. Targeting endoplasmic reticulum signaling pathways in cancer. Acta Oncol. 51:822-830.

Meredith, J. E. Jr, B. Fazeli, and M. A. Schwartz. 1993. The extracellular matrix as a cell survival factor. Mol. Biol. Cell 4:953-961. 
Metro, G., Z. Zheng, A. Fabi, M. Schell, B. Antoniani, M. Mottolese, A. N. Monteiro, P. Vici, S. Lara Rivera, D. Boulware, F. Cognetti, and G. Bepler. 2010. In situ protein expression of RRM1, ERCC1, and BRCA1 in metastatic breast cancer patients treated with gemcitabine-based chemotherapy. Cancer Invest. 28:172-180.

Mossberg, A. K., Y. Hou, M. Svensson, B. Holmqvist, and C. Svanborg. 2010a. HAMLET treatment delays bladder cancer development. J. Urol. 183:1590-1597.

Mossberg, A. K., M. Puchades, Ø. Halskau, A. Baumann, I. Lanekoff, Y. Chao, A. Martinez, C. Svanborg, and R. Karlsson. 2010b. HAMLET interacts with lipid membranes and perturbs their structure and integrity. PLoS ONE 5:e9384.

Nagaraj, N. S., O. V. Singh, and N. B. Merchant. 2010. Proteomics: a strategy to understand the novel targets in protein misfolding and cancer therapy. Expert Rev. Proteomics 7:613-623.

Naora, H., I. Takai, M. Adachi, and H. Naora. 1998. Altered cellular responses by varying expression of a ribosomal protein gene: Sequential coordination of enhancement and suppression of ribosomal protein S3a gene expression induces apoptosis. J. Cell Biol. 141:741-753.

Nasir, J., S. B. Floresco, J. R. O'Kusky, V. M. Diewert, J. M. Richman, J. Zeisler, A. Borowski, J. D. Marth, A. G. Phillips, and M. R. Hayden. 1995. Targeted disruption of the Huntington's disease gene results in embryonic lethality and behavioral and morphological changes in heterozygotes. Cell 81:811-823.

Navarra, P., and P. Preziosi. 1999. Hydroxyurea: New insights on an old drug. Crit. Rev. Oncol. Hematol. 29:249-255.

Nolte, D., G. Taimor, M. Kalff-Suske, and K. H. Seifart. 1996. The human S3a ribosomal protein: sequence, location and cell-free transcription of the functional gene. Gene 169:179-185.

Ohl, F., M. Jung, A. Radonić, M. Sachs, S. A. Loening, and K. Jung. 2006. Identification and validation of suitable endogenous reference genes for gene expression studies of human bladder cancer. J. Urol. 175:1915-1920.

Ohl, F., M. Jung, C. Xu, C. Stephan, A. Rabien, M. Burkhardt, A. Nitsche, G. Kristiansen, S. A. Loening, A. Radonić, and K. Jung. 2005. Gene expression studies in prostate cancer tissue: which reference gene should be selected for normalization? J. Mol. Med. (Berl) 83:1014-1024.

Okar, D. A., and A. J. Lange. 1999. Fructose-2,6-bisphosphate and control of carbohydrate metabolism in eukaryotes. Biofactors 10:1-14.

Parker, N. J., C. G. Begley, and R. M. Fox. 1995. Human gene for the large subunit of ribonucleotide reductase (RRM1): functional analysis of the promoter. Genomics 27:280-285.

Permana, S., S. Hisanaga, Y. Nagatomo, J. Iida, H. Hotani, and T. J. Itoh. 2005. Truncation of the projection domain of MAP4 (microtubule-associated protein 4) leads to attenuation of microtubule dynamic instability. Cell Struct. Funct. 29:147-157.

Rattner, J. B., A. Rao, M. J. Fritzler, D. W. Valencia, and T. J. Yen. 1993. CENP-F is a ca $400 \mathrm{kDa}$ kinetochore protein that exhibits a cell-cycle dependent localization. Cell Motil. Cytoskeleton 26:214-226.

Rider, M. H., L. Bertrand, D. Vertommen, P. A. Michels, G. G. Rousseau, and L. Hue. 2004. 6-phosphofructo-2-kinase/fructose-2,6bisphosphatase: Head-to-head with a bifunctional enzyme that controls glycolysis. Biochem. J. 381:561-579.

Ros, S., and A. Schulze. 2013. Balancing glycolytic flux: The role of 6-phosphofructo-2-kinase/fructose 2,6-bisphosphatases in cancer metabolism. Cancer Metab. 1:8.

Ross, C. A., and S. J. Tabrizi. 2011. Huntington's disease: from molecular pathogenesis to clinical treatment. Lancet Neurol. 10:83-98.

Sattler, U. G., S. S. Meyer, V. Quennet, C. Hoerner, H. Knoerzer, C. Fabian, A. Yaromina, D. Zips, S. Walenta, M. Baumann, and W. Mueller-Klieser. 2010. Glycolytic metabolism and tumour response to fractionated irradiation. Radiother. Oncol. 94:102-109.

Shenoy, N., R. Kessel, T. D. Bhagat, S. Bhattacharyya, Y. Yu, C. McMahon, and A. Verma. 2012. Alterations in the ribosomal machinery in cancer and hematologic disorders. J. Hematol. Oncol. 5:32.

Simons, K., and E. Ikonen. 1997. Functional rafts in cell membranes. Nature 387:569-572.
Sims, A. E., E. Spiteri, R. J. Sims 3rd, A. G. Arita, F. P. Lach, T. Landers, M. Wurm, M. Freund, K. Neveling, H. Hanenberg, A. D. Auerbach, and T. T. Huang. 2007. FANCI is a second monoubiquitinated member of the Fanconi anemia pathway. Nat. Struct. Mol. Biol. 14:564-567.

Smogorzewska, A., S. Matsuoka, P. Vinciguerra, E. R. McDonald 3rd, K. E. Hurov, J. Luo, B. A. Ballif, S. P. Gygi, K. Hofmann, A. D. D'Andrea, and S. J. Elledge. 2007. Identification of the FANCI protein, a monoubiquitinated FANCD2 paralog required for DNA repair. Cell 129:289-301.

Steller. H. 1995. Mechanisms and genes of cellular suicide. Science 267:1445-1449.

Storm, P. 2012. The mechanism of HAMLET-induced cell death-cellular signalling, oncogenes and clinical perspectives. $\mathrm{PhD}$ Thesis. Lund University, Lund, Sweden.

Storm, P., S. Aits, M. K. Puthia, A. Urbano, T. Northen, S. Powers, B. Bowen, Y. Chao, W. Reindl, D. Y. Lee, N. L. Sullivan, J. Zhang, M. Trulsson, H. Yang, J. D. Watson, and C. Svanborg. 2011. Conserved features of cancer cells define their sensitivity to HAMLETinduced death; c-Myc and glycolysis. Oncogene 30:4765-4779.

Stupack, D. G., and D. A. Cheresh. 2002. Get a ligand, get a life: Integrins, signaling and cell survival. J. Cell Sci. 115:3729-3738.

Svanborg, C., H. Agerstam, A. Aronson, R. Bjerkvig, C. Düringer, W. Fischer, L. Gustafsson, O. Hallgren, I. Leijonhuvud, S. Linse, A. K. Mossberg, H. Nilsson, J. Pettersson, and M. Svensson. 2003. HAMLET kills tumor cells by an apoptosis-like mechanismCellular, molecular, and therapeutic aspects. Adv. Cancer Res. 88:1-29.

Svensson, M., C. Düringer, O. Hallgren, A. K. Mossberg, A. Håkansson, S. Linse, and C. Svanborg. 2002. Hamlet-A complex from human milk that induces apoptosis in tumor cells but spares healthy cells. Adv. Exp. Med. Biol. 503:125-132.

Svensson, M., A. Håkansson, A. K. Mossberg, S. Linse, and C. Svanborg. 2000. Conversion of $\alpha$-lactalbumin to a protein inducing apoptosis. Proc. Natl. Acad. Sci. USA 97:4221-4226.

Thiery, J. P., and J. P. Sleeman. 2006. Complex networks orchestrate epithelial-mesenchymal transitions. Nat. Rev. Mol. Cell Biol. $7: 131-142$.

Thornton, J. E., H. M. Chang, E. Piskounova, and R. I. Gregory. 2012. Lin28-mediated control of let-7 microRNA expression by alternative TUTases Zcchc11 (TUT4) and Zcchc6 (TUT7). RNA 18:1875-1885.

Tian, W. N., L. D. Braunstein, J. Pang, K. M. Stuhlmeier, Q. C. Xi, X. Tian, and R. C. Stanton. 1998. Importance of glucose-6-phosphate dehydrogenase activity for cell growth. J. Biol. Chem. 273:1060910617.

Tolin, S., G. De Franceschi, B. Spolaore, E. Frare, C. Marcella, P. P. De Laureto, and A. Fontana. 2010. The oleic acid complexes of proteolytic fragments of $\alpha$-lactalbumin display apoptotic activity. FEBS J. 277:163-173.

Velier, J., M. Kim, C. Schwarz, T. W. Kim, E. Sapp, K. Chase, N. Aronin, and M. DiFiglia. 1998. Wild-type and mutant huntingtins function in vesicle trafficking in the secretory and endocytic pathways. Exp. Neurol. 152:34-40.

Waelter, S., E. Scherzinger, R. Hasenbank, E. Nordhoff, R. Lurz, H. Goehler, C. Gauss, K. Sathasivam, G. P. Bates, H. Lehrach, and E. E. Wanker. 2001. The huntingtin interacting protein HIP1 is a clathrin and alpha-adaptin-binding protein involved in receptormediated endocytosis. Hum. Mol. Genet. 10:1807-1817.

Wang, G., Z. Q. Yang, and K. Zhang. 2010. Endoplasmic reticulum stress response in cancer: molecular mechanism and therapeutic potential. Am. J. Transl. Res. 2:65-74.

Wang, J., and M. J. Lenardo. 2000. Roles of caspases in apoptosis, development, and cytokine maturation revealed by homozygous gene deficiencies. J. Cell Sci. 113:753-757.

Wang, W. A., J. Groenendyk, and M. Michalak. 2014. Endoplasmic reticulum stress associated responses in cancer. Biochim. Biophys. Acta 1843:2143-2149.

Welner, S., N. H. Trier, M. Frisch, H. Locht, P. R. Hansen, and G. Houen. 2013. Correlation between centromere protein-F autoanti- 
bodies and cancer analyzed by enzyme-linked immunosorbent assay. Mol. Cancer 12:95.

Wolfe, R. R. 1998. Metabolic interactions between glucose and fatty acids in humans. Am. J. Clin. Nutr. 67:519S-526S.

Yalcin, A., S. Telang, B. Clem, and J. Chesney. 2009. Regulation of glucose metabolism by 6-phosphofructo-2-kinase/fructose-2,6bisphosphatases in cancer. Exp. Mol. Pathol. 86:174-179.

Yilmaz, M., and G. Christofori. 2009. EMT, the cytoskeleton, and cancer cell invasion. Cancer Metastasis Rev. 28:15-33.

Zhang, G. B., J. Chen, L. R. Wang, J. Li, M. W. Li, N. Xu, Y. Wang, and J. Z. Shentu. 2012. RRM1 and ERCC1 expression in peripheral blood versus tumor tissue in gemcitabine/carboplatin-treated advanced non-small cell lung cancer. Cancer Chemother. Pharmacol. 69:1277-1287.

Zhang, H., Q. Wang, K. Kajino, and M. I. Greene. 2000. VCP, a weak ATPase involved in multiple cellular events, interacts physically with BRCA1 in the nucleus of living cells. DNA Cell Biol. 19:253-263.

Zhang, Y. B., J. L. Gong, T. Y. Xing, S. P. Zheng, and W. Ding. 2013. Autophagy protein p62/SQSTM1 is involved in HAMLET- induced cell death by modulating apotosis in U87MG cells. Cell Death Dis. 4:e550.

Zherelova, O. M., A. A. Kataev, V. M. Grishchenko, E. L. Knyazeva, S. E. Permyakov, and E. A. Permyakov. 2009. Interaction of antitumor alpha-lactalbumin-oleic acid complexes with artificial and natural membranes. J. Bioenerg. Biomembr. 41:229-237.

Zhou, H., Y. Zhang, Y. Fu, L. Chan, and A. S. Lee. 2011. Novel mechanism of anti-apoptotic function of 78-kDa glucose-regulated protein (GRP78): Endocrine resistance factor in breast cancer, through release of B-cell lymphoma 2 (BCL-2) from BCL-2-interacting killer (BIK). J. Biol. Chem. 286:25687-25696.

Zhou, X., R. Wang, L. Fan, Y. Li, L. Ma, Z. Yang, W. Yu, N. Jing, and X. Zhu. 2005. Mitosin/CENP-F as a negative regulator of activating transcription factor-4. J. Biol. Chem. 280:13973-13977.

Zieske, L. R. 2006. A perspective on the use of $\mathrm{iTRAQ}^{\mathrm{TM}}$ reagent technology for protein complex and profiling studies. J. Exp. Bot. 57:1501-1508. 